\title{
Synthesis and Cytotoxic Studies of Undecenoic Acid- based Schiff's Base Derivatives Bearing 1,2,4-Triazole Moiety
}

\author{
V. VENEPALLY ${ }^{1}$, S. K. NETHI ${ }^{1,3}$, K. PALLAVI ${ }^{2}$, C. R. PATRA ${ }^{1,3}$ AND R. C. R. JALA ${ }^{3 *}$ \\ Centre for Lipid Research, ${ }^{1}$ Chemical Biology Division, CSIR-Indian Institute of Chemical Technology, Hyderabad-500 007 , \\ ${ }^{2}$ Raja Bahadur Venkata Rama Reddy Women's College, Narayanguda, Hyderabad-500 029, ${ }^{3}$ Academy of Scientific and
} Innovative Research, Ghaziabad-201 002, India

Venepally et al.: Undecenoic acid-based Schiff's base derivatives

\begin{abstract}
A series of novel 1,2,4-triazole-based schiff's base derivatives were synthesized by condensing undecenoic triazole compound with various substituted benzaldehydes. Compounds so synthesized were thoroughly characterized using ${ }^{1} \mathrm{H}$ nuclear magnetic resonance, ${ }^{13} \mathrm{C}$ nuclear magnetic resonance, high resolution mass spectrometry and Fourier transform-infrared spectroscopy. Cytotoxicity of these compounds was tested in vitro on three cancer cell lines, mouse melanoma cancer cells (B16 F10), human colon cancer cells (HCT15), human ovarian cancer cell line (SKOV3) and normal mouse embryonic fibroblasts (NIH-3T3) using 3-(4,5-dimethylthiazol-2-yl)-2,5-diphenyltetrazolium bromide assay. The results showed that most of the compounds exhibited cytotoxicity against the tested cell lines. Among the tested compounds, $6 \mathrm{~g}$ and $6 \mathrm{n}$ showed significant cytotoxicity against B16 F10 cells and compounds 6i, 6n, 60, 6p and 6q against HCT-15 cell line. The Schiff's base derivative 6g, appeared to be the most effective on B16 F10 cancer cells due to bromo substitution on the 4th position of the phenyl ring. Altogether, the cytotoxicity of these compounds observed against cancer cells indicate anticancer potential.
\end{abstract}

Key words: Undecenoic acid, 1,2,4-triazole, schiff's base, anticancer, cytotoxicity

Cancer continues to be a serious health problem in the developed and the developing countries. It is now the most common cause of death worldwide. The current human lifestyle has played a key role in the increasing rate of cancer. Therefore, continuous efforts are needed to discover novel compounds with improved selectivity and activity by chemical modifications. 1,2,4-Triazole nucleus represent an important class of heterocyclic compounds and their derivatives are characterized with a broad spectrum of biological activities including antibacterial, antifunga ${ }^{[1]}$, antitubercular ${ }^{[2]}$, anticancer ${ }^{[3]}$, anticonvulsant ${ }^{[4]}$, antiinflammatory ${ }^{[5]}$, analgesic ${ }^{[6]}$ and molluscicidal properties $^{[7-10]}$. Various studies reported synthesis and pharmacological activities of 4-amino-1,2,4-triazole5 -thione moiety. This core structural unit was present in a diverse molecules that showed a wide range of activities namely, antifungal ${ }^{[11]}$, antibacterial ${ }^{[12-16]}$, anticancer ${ }^{[17,18]}$, antitubercular ${ }^{[19]}$, antiinflammatory ${ }^{[20]}$, antimolluscicidal $^{[21]}$, antiviral ${ }^{[22,23]}$ and antioxidant ${ }^{[24]}$.

In addition, Schiff's bases form an important class of organic compounds exhibiting a wide range of applications. Schiff's bases have also gained importance in medicinal and pharmaceutical fields due to a broad spectrum of activities that these compounds exhibited, which included antiinflammatory ${ }^{[25-28]}$, analgesic ${ }^{[26-29]}$, antimicrobial ${ }^{[30,31]}$, anticonvulsant ${ }^{[32]}$, antitubercular ${ }^{[33]}$, anticancer $^{[34,35]}$, antioxidant ${ }^{[36]}$ and anthelmintic ${ }^{[37]}$. Apart from the above mentioned biological activities, Schiff's bases have also been used as catalysts, intermediates in organic synthesis, dyes, pigments, polymer stabilizers and corrosion inhibitors ${ }^{[38]}$. Schiff's base metal complexes also showed greater biological activity than free organic compounds ${ }^{[39]}$.

On the other hand, fatty acids and their derivatives are known to possess antimicrobial[ ${ }^{[40,41]}$, antifungal ${ }^{[42]}$, and pesticidal ${ }^{[43]}$ activities. Undecenoic acid was found to exhibit several biological activities such as

This is an open access article distributed under the terms of the Creative Commons Attribution-NonCommercial-ShareAlike 3.0 License, which allows others to remix, tweak, and build upon the work non-commercially, as long as the author is credited and the new creations are licensed under the identical terms

Accepted 22 June 2019

Revised 28 March 2019

Received 23 December 2018

Indian J Pharm Sci 2019;81(4):737-746 
antifungal, antibacterial and antiviral. The derivatives of undecenoic acid also affect cellular processes related to cancer ${ }^{[4-46]}$. Literature revealed that a variety of modified fatty acid were promising molecules in cancer prevention and have the potential to treat cancers ${ }^{[4,47,48]}$. In the light of these interesting biological activities associated with 1,2,4-triazole, Schiff's bases and undecenoic acid, it was planned in the present study to synthesize some novel Schiff's base derivatives bearing 1,2,4-triazole and undecenoic moieties and to evaluate the cytotoxicity possessed by these derivatives towards cancer and normal cells.

\section{MATERIALS AND METHODS}

All the chemicals used in these schemes were of analytical grade, which were obtained from different commercial sources and used without any further purification. Reactions were monitored on micro TLC plates (coated with TLC grade silica gel, obtained from Merck). Column chromatography was performed using silica gel (100-200 mesh) procured from Qualigens (India) using freshly distilled solvents. All ${ }^{1} \mathrm{H}$-nuclear magnetic resonance (NMR) and ${ }^{13} \mathrm{C}$-NMR spectra were recorded with a Bruker Avance (for ${ }^{1} \mathrm{H}-\mathrm{NMR}$ at $300 \mathrm{MHz}, 400 \mathrm{MHz}, 500 \mathrm{MHz}$ and for ${ }^{13} \mathrm{C}-\mathrm{NMR}$ at $75 \mathrm{MHz}, 100 \mathrm{MHz}, 125 \mathrm{MHz}$ ) spectrometer, using TMS $\delta=0 \mathrm{ppm}$ and $\delta 77.00 \mathrm{ppm}$ as internal standard for chemical shifts $(\delta)$ in $\mathrm{CDCl}_{3}$ at $25^{\circ}$. The chemical shift values are presented in ppm (parts per million) units. Mass spectra were recorded with high resolution mass spectra (HRMS). IR spectra were recorded in chloroform on a Perkin-Elmer Fourier-transform infrared spectroscopy (FTIR) spectrum BX.

\section{Synthesis of methyl undec-10-enoate (2):}

To a stirred solution of undec-10-enoic acid $(73.45 \mathrm{mmol})$ in methanol $(100 \mathrm{ml})$, a few drops of concentrated $\mathrm{H}_{2} \mathrm{SO}_{4}$ was added. The reaction mixture was refluxed for $10 \mathrm{~h}$. Progress of the reaction was monitored by micro TLC. After completion of the reaction, methanol was removed under reduced pressure and water was added and the title compound was extracted with ethyl acetate, dried over anhydrous sodium sulphate and concentrated under vacuum to afford the title compound. ${ }^{1} \mathrm{H} \mathrm{NMR}\left(300 \mathrm{MHz}, \mathrm{CDCl}_{3}\right)$ : $\delta(\mathrm{ppm})=5.75-5.85\left(\mathrm{~m},-\mathrm{CH}=\mathrm{CH}_{2}-, 1 \mathrm{H}\right), 4.91-5.01$ (m, $\left.-\mathrm{CH}=\mathrm{CH}_{2}-, 2 \mathrm{H}\right), 3.66\left(\mathrm{~s},-\mathrm{OCH}_{3}, 3 \mathrm{H}\right), 2.28-2.31$ (t, $\left.-\mathrm{CH}_{2}^{-}, J=7.4 \mathrm{~Hz}, 2 \mathrm{H}\right), 2.01-2.06\left(\mathrm{~m},-\mathrm{CH}_{2}-, 2 \mathrm{H}\right)$, 1.59-1.65 (m, - $\left.\mathrm{CH}_{2}^{-}, 2 \mathrm{H}\right), 1.26-1.39\left(\mathrm{~m},-\left(\mathrm{CH}_{2}\right)_{5}^{-}\right.$, $10 \mathrm{H})$. electrospray ionization (ESI)-MS: $[\mathrm{M}+\mathrm{H}]^{+}$ $m / z=199$. $(59.93 \mathrm{mmol})$ in ethanol $(90 \mathrm{ml})$, hydrazine hydrate (269.68 mmol) was added. The reaction mixture was refluxed for about $10 \mathrm{~h}$. Progress of the reaction was monitored by micro TLC. After completion of reaction, the solvent was evaporated under reduced pressure, ice water $(50 \mathrm{ml})$ was added and the mixture was stirred for $15 \mathrm{~min}$. The solid obtained was filtered and dried under vacuum to yield undec-10-enehydrazide as a white solid. ${ }^{1} \mathrm{H}$ NMR $\left(300 \mathrm{MHz}, \mathrm{CDCl}_{3}\right): \delta(\mathrm{ppm})=5.75-5.85$ (m, $\left.-\mathrm{CH}=\mathrm{CH}_{2}-1 \mathrm{H}\right), 4.91-5.01$ (m, $\left.-\mathrm{CH}=\mathrm{CH}_{2}, 2 \mathrm{H}\right)$, 2.67-3.01 (broad-s, $\left.-\mathrm{NH}_{2}, 2 \mathrm{H}\right), 2.12-2.16$ (t, $-\mathrm{CH}_{2}$, $J=7.3 \mathrm{~Hz}, 2 \mathrm{H}), 2.00-2.06\left(\mathrm{~m},-\mathrm{CH}_{2}-, 2 \mathrm{H}\right), 1.59-1.66$ (m, $\left.-\mathrm{CH}_{2}-, 2 \mathrm{H}\right), 1.25-1.38\left(\mathrm{~m},-\left(\mathrm{CH}_{2}\right)_{5}-, 10 \mathrm{H}\right)$. ESI-MS: $[\mathrm{M}+\mathrm{H}]^{+} m / z=199$.

\section{Synthesis of potassium 2-(undec-10-enoyl) hydrazine-1-carbodithioate (4):}

Potassium hydroxide pellets $(106.54 \mathrm{mmol})$ were dissolved in ethanol $(40 \mathrm{ml})$. To this solution, undec10-enehydrazide (53.27 mmol), carbon disulphide (117.19 mmol) were added successively and the contents were stirred at room temperature for $8 \mathrm{~h}$. Progress of the reaction was monitored by micro TLC. After completion of the reaction, diethyl ether $(100 \mathrm{ml})$ was added to the reaction mixture and stirred for $10 \mathrm{~min}$. After filtration, potassium 2-(undec-10enoyl) hydrazine-1-carbodithioate was obtained as an off-white solid.

Synthesis of 4-amino-5-(dec-9-en-1-yl)-4H-1,2,4triazole-3-thiol (5):

Hydrazine hydrate $(45.38 \mathrm{mmol})$ was added to potassium 2-(undec-10-enoyl) hydrazine-1-carbodithioate $(45.38 \mathrm{mmol})$ and the contents were refluxed for $5 \mathrm{~h}$. Progress of the reaction was monitored by micro TLC. After completion of reaction, the reaction mixture was acidified with concentrated hydrochloric acid. The obtained precipitate was filtered and dried under vacuum to obtain the crude compound, which was subjected to silica gel column chromatography and the required product was eluted in a solvent mixture (hexane:EtOAc, 85:15, v/v) as an off white solid. ESIMS: $[\mathrm{M}+\mathrm{H}]^{+} m / z=255$.

\section{General procedure for the synthesis of} benzylideneamine derivatives (6a-6t):

To a stirred solution of compound $5(4.84 \mathrm{mmol})$ in ethanol $(10 \mathrm{ml})$, benzaldehyde (1 equivalent) and two 
to three drops of concentrated $\mathrm{H}_{2} \mathrm{SO}_{4}$ were added and the contents were refluxed for $6 \mathrm{~h}$. The reaction was monitored by micro TLC. After completion of reaction, the solvent was removed under reduced pressure. To the residue, $5 \mathrm{ml}$ of ice water was added, stirred for $5 \mathrm{~min}$, and the precipitated solid was filtered and dried under vacuum. The compounds were purified by silica gel column chromatography using ethyl acetate and hexane as a solvent mixture.

\section{4-Bromo-2-(((3-(dec-9-en-1-yl)-5-mercapto-4H- 1,2,4-triazol-4-yl)imino)methyl)phenol (6a):}

The crude compound was subjected to silica gel column chromatography and the required product was eluted in a solvent mixture (hexane:EtOAc, 70:30, v/v) as an off white solid with $81 \%$ yield. ${ }^{1} \mathrm{H}-\mathrm{NMR}$ data $(500 \mathrm{MHz}$, $\left.\mathrm{CDCl}_{3}\right): \delta(\mathrm{ppm})=10.37(\mathrm{~s},-\mathrm{SH}, 1 \mathrm{H}), 10.26(\mathrm{~s},-\mathrm{CH}=\mathrm{N}-$, $1 \mathrm{H}), 7.52-7.56(\mathrm{~m}, \mathrm{Ar}-\mathrm{H}, 2 \mathrm{H}), 6.96(\mathrm{~d}, \mathrm{Ar}-\mathrm{H}, J=$ $8.6 \mathrm{~Hz}, 1 \mathrm{H}), 5.75-5.84\left(\mathrm{~m},-\mathrm{CH}=\mathrm{CH}_{2}-, 1 \mathrm{H}\right), 4.91-5.00$ $\left(\mathrm{m},-\mathrm{CH}=\mathrm{CH}_{2}-, 2 \mathrm{H}\right), 2.74-2.77\left(\mathrm{t},-\mathrm{CH}_{2}-, J=7.4 \mathrm{~Hz}\right.$, $2 \mathrm{H}), 2.00-2.04\left(\mathrm{~m},-\mathrm{CH}_{2}-, 2 \mathrm{H}\right), 1.71-1.77\left(\mathrm{~m},-\mathrm{CH}_{2}^{-}\right.$, $2 \mathrm{H}), 1.25-1.40\left(\mathrm{~m},-\left(\mathrm{CH}_{2}\right)_{5}-, 10 \mathrm{H}\right) ;{ }^{13} \mathrm{C} \mathrm{NMR}(75 \mathrm{MHz}$, $\left.\mathrm{CDCl}_{3}\right): \delta(\mathrm{ppm})=159.7,155.9,149.7,137.1,134.2$, $127.4,119.1,118.0,117.1,112.6,109.4,31.7,29.8$, 27.2, 27.0, 26.8, 24.0, 23.0, 20.6; IR $\left(\mathrm{CHCl}_{3} v_{\max } \mathrm{cm}^{-1}\right)$ : 3412, 2854, 2254, 2128, 1652, 1420, 1115, 1026, 825, 764, 625; HR-MS (ESI) $m / z$ [M-H $\left.{ }^{+}\right]: 435.13823$.

\section{5-(Dec-9-en-1-yl)-4-((4-nitrobenzylidene)amino)- 4H-1,2,4-triazole-3-thiol (6b):}

The crude compound was subjected to silica gel column chromatography and the required product was eluted in a solvent mixture (hexane:EtOAc, 75:25, v/v) as a light yellow solid with $79 \%$ yield. ${ }^{1} \mathrm{H}-\mathrm{NMR}$ data $(500 \mathrm{MHz}$, $\left.\mathrm{CDCl}_{3}\right): \delta(\mathrm{ppm})=10.92(\mathrm{~s},-\mathrm{CH}=\mathrm{N}-, 1 \mathrm{H}), 8.35(\mathrm{~d}, \mathrm{Ar}-$ $\mathrm{H}, J=8.5 \mathrm{~Hz}, 2 \mathrm{H}), 8.03$ (d, Ar-H, $J=8.5 \mathrm{~Hz}, 2 \mathrm{H}), 5.75-$ $5.83\left(\mathrm{~m},-\mathrm{CH}=\mathrm{CH}_{2}-, 1 \mathrm{H}\right), 4.91-5.00\left(\mathrm{~m},-\mathrm{CH}=\mathrm{CH}_{2}-\right.$, $2 \mathrm{H}), 2.83-2.86\left(\mathrm{t},-\mathrm{CH}_{2^{-}}, J=7.4 \mathrm{~Hz}, 2 \mathrm{H}\right), 2.00-2.05(\mathrm{~m}$, $\left.-\mathrm{CH}_{2}-, 2 \mathrm{H}\right), 1.74-1.80\left(\mathrm{~m},-\mathrm{CH}_{2}-, 2 \mathrm{H}\right), 1.25-1.43(\mathrm{~m}$, $\left.-\left(\mathrm{CH}_{2}\right)_{5}-, 10 \mathrm{H}\right) ;{ }^{13} \mathrm{C} \mathrm{NMR}\left(100 \mathrm{MHz}, \mathrm{CDCl}_{3}\right): \delta(\mathrm{ppm})=$ 162.2, 156.2, 153.1, 149.7, 139.0, 130.4, 129.1, 124.1, $114.1,33.7,31.8,29.2,28.9,28.8,25.9,24.9,22.6$; IR $\left(\mathrm{CHCl}_{3} v_{\max } \mathrm{cm}^{-1}\right): 3398,2923,2854,2109,1581$, 1525, 1468, 1345, 1275, 1110, 844, 749; HR-MS (ESI) $m / z\left[\mathrm{M}+\mathrm{H}^{+}\right]$: calc for $\mathrm{C}_{19} \mathrm{H}_{26} \mathrm{O}_{2} \mathrm{~N}_{5} \mathrm{~S}$ is 388.18017 found $388.17969\left(\mathrm{C}_{28} \mathrm{H}_{41} \mathrm{FN}_{2} \mathrm{O}_{4} \mathrm{Na}\right)$.

\section{2,4-Dichloro-6-(((3-(dec-9-en-1-yl)-5-mercapto-4H- 1,2,4-triazol-4-yl)imino)methyl)phenol (6c):}

The crude compound was subjected to silica gel column chromatography and the required product was eluted in a solvent mixture (hexane:EtOAc, $70: 30, \mathrm{v} / \mathrm{v})$ as an off white solid with $73 \%$ yield. ${ }^{1} \mathrm{H}-\mathrm{NMR}$ data $\left(400 \mathrm{MHz}, \mathrm{CDCl}_{3}\right): \delta(\mathrm{ppm})=10.69$ (s, -SH, 1H), 10.60 (s, -CH=N-, 1H), 7.54 (s, Ar-H, $1 \mathrm{H}), 7.38(\mathrm{~s}, \mathrm{Ar}-\mathrm{H}, 1 \mathrm{H}), 5.75-5.84\left(\mathrm{~m},-\mathrm{CH}=\mathrm{CH}_{2}^{-}\right.$, $1 \mathrm{H}), \quad 4.91-5.01 \quad\left(\mathrm{~m}, \quad-\mathrm{CH}=\mathrm{CH}_{2}-, \quad 2 \mathrm{H}\right), \quad 2.75-2.78$ (t, $\left.-\mathrm{CH}_{2}-, J=7.4 \mathrm{~Hz}, 2 \mathrm{H}\right), 2.00-2.05\left(\mathrm{~m},-\mathrm{CH}_{2}-, 2 \mathrm{H}\right)$, $1.72-1.79\left(\mathrm{~m},-\mathrm{CH}_{2}-, 2 \mathrm{H}\right), 1.25-1.43\left(\mathrm{~m},-\left(\mathrm{CH}_{2}\right)_{5}^{-}\right.$, $10 \mathrm{H}) ;{ }^{13} \mathrm{C}$ NMR $\left(100 \mathrm{MHz}, \mathrm{CDCl}_{3}\right): \delta(\mathrm{ppm})=162.6$, $161.9,153.7,151.6,139.0,133.9,130.7,124.9,123.1$, $117.8,114.1,33.7,31.8,29.1,28.9,28.8,25.6,25.0$, 22.6; IR $\left(\mathrm{CHCl}_{3} v_{\max } \mathrm{cm}^{-1}\right): 3401,2926,2854,2110$, 1603, 1459, 1273, 1161, 1024, 738; HR-MS (ESI) $\mathrm{m} / \mathrm{z}$ $\left[\mathrm{M}-\mathrm{H}^{+}\right]: 425.14937$.

\section{4-Chloro-2-(((3-(dec-9-en-1-yl)-5-mercapto-4H- 1,2,4-triazol-4-yl)imino)methyl)phenol (6d):}

The crude compound was subjected to silica gel column chromatography and the required product was eluted in a solvent mixture (hexane:EtOAc, 70:30, v/v) as an off white solid with $76 \%$ yield. ${ }^{1} \mathrm{H}-\mathrm{NMR}$ data $\left(400 \mathrm{MHz}, \mathrm{CDCl}_{3}\right): \delta(\mathrm{ppm})=10.37(\mathrm{~s},-\mathrm{SH}, 1 \mathrm{H}), 10.24$ $(\mathrm{s},-\mathrm{CH}=\mathrm{N}-, 1 \mathrm{H}), 7.39-7.41$ (m, Ar-H and $-\mathrm{OH}, 3 \mathrm{H})$, 7.00 (d, Ar-H, $J=8.5 \mathrm{~Hz}, 1 \mathrm{H}), 5.75-5.85$ (m, $-\mathrm{CH}=\mathrm{CH}_{2}-$, 1H), 4.92-5.00 (m, $\left.-\mathrm{CH}=\mathrm{CH}_{2}-, 2 \mathrm{H}\right), 2.73-2.77\left(\mathrm{t},-\mathrm{CH}_{2}-\right.$, $J=7.4 \mathrm{~Hz}, 2 \mathrm{H}), 2.00-2.04\left(\mathrm{~m},-\mathrm{CH}_{2}-, 2 \mathrm{H}\right), 1.72-1.78$ (m, $\left.-\mathrm{CH}_{2}-, 2 \mathrm{H}\right), 1.25-1.43\left(\mathrm{~m},-\left(\mathrm{CH}_{2}\right)_{5}-, 10 \mathrm{H}\right) ;{ }^{13} \mathrm{C} \mathrm{NMR}$ $\left(125 \mathrm{MHz}, \mathrm{CDCl}_{3}\right): \delta(\mathrm{ppm})=163.8,162.3,158.1$, $151.5,139.0,134.2,132.2,124.9,119.0,117.0,114.1$, 33.7, 31.8, 29.1, 28.9, 28.2, 25.7, 25.1, 22.6; IR $\left(\mathrm{CHCl}_{3}\right.$ $\left.v_{\max } \mathrm{cm}^{-1}\right): 3149,2927,2855,1597,1479,1425,1352$, 1276, 1166, 1118, 1016, 915, 828, 660; HR-MS (ESI) $\mathrm{m} / \mathrm{z}\left[\mathrm{M}+\mathrm{H}^{+}\right]$: calc for $\mathrm{C}_{19} \mathrm{H}_{26} \mathrm{ON}_{4} \mathrm{ClS}$ is 393.15104 found $393.15140\left(\mathrm{C}_{19} \mathrm{H}_{26} \mathrm{ON}_{4} \mathrm{ClS}\right)$.

\section{5-(Dec-9-en-1-yl)-4-((3-nitrobenzylidene)amino)- 4H-1,2,4-triazole-3-thiol (6e):}

The crude compound was subjected to silica gel column chromatography and the required product was eluted in a solvent mixture (hexane:EtOAc, 75:25, v/v) as a light yellow solid with $73 \%$ yield. ${ }^{1} \mathrm{H}-\mathrm{NMR}$ Data $(400 \mathrm{MHz}$, $\left.\mathrm{CDCl}_{3}\right): \delta(\mathrm{ppm})=10.86(\mathrm{~s},-\mathrm{CH}=\mathrm{N}-, 1 \mathrm{H}), 8.72(\mathrm{~s}, \mathrm{Ar}-$ $\mathrm{H}, 1 \mathrm{H}), 8.36-8.39$ (m, Ar-H, , 1H), 8.14-8.16 (d, Ar-H, $J=7.7 \mathrm{~Hz}, 1 \mathrm{H}), 7.67-7.71$ (t, Ar-H, 1H), 5.74-5.84 (m, $\left.-\mathrm{CH}=\mathrm{CH}_{2}-, 1 \mathrm{H}\right), 4.93-5.00\left(\mathrm{~m},-\mathrm{CH}=\mathrm{CH}_{2}-, 2 \mathrm{H}\right), 2.84-$ $2.88\left(\mathrm{t},-\mathrm{CH}_{2}^{-}, J=7.4 \mathrm{~Hz}, 2 \mathrm{H}\right), 1.99-2.04\left(\mathrm{~m},-\mathrm{CH}_{2}-\right.$, $2 \mathrm{H}), 1.74-1.82\left(\mathrm{~m},-\mathrm{CH}_{2}-, 2 \mathrm{H}\right), 1.25-1.44\left(\mathrm{~m},-\left(\mathrm{CH}_{2}\right)_{5}-\right.$, $10 \mathrm{H}) ;{ }^{13} \mathrm{C} \mathrm{NMR}\left(125 \mathrm{MHz}, \mathrm{CDCl}_{3}\right): \delta(\mathrm{ppm})=162.0$, 156.7, 153.0, 148.6, 139.0, 134.5, 134.1, 130.0, 126.3, 122.7, 114.0, 33.6, 31.7, 29.1, 28.9, 28.7, 25.9, 24.9, 
22.5; IR $\left(\mathrm{CHCl}_{3} v_{\max } \mathrm{cm}^{-1}\right): 3106,2926,2854,1613$, 1584, 1536, 1414, 1352, 1287, 1094, 808, 734; HR-MS (ESI) $m / z\left[\mathrm{M}+\mathrm{H}^{+}\right]$: calc for $\mathrm{C}_{19} \mathrm{H}_{26} \mathrm{O}_{2} \mathrm{~N}_{5} \mathrm{~S}$ is 388.18017 found $388.17969\left(\mathrm{C}_{19} \mathrm{H}_{26} \mathrm{O}_{2} \mathrm{~N}_{5} \mathrm{~S}\right)$.

\section{5-(Dec-9-en-1-yl)-4-((2,4,6-trifluorobenzylidene) amino)-4H-1,2,4-triazole-3-thiol (6f):}

The crude compound was subjected to silica gel column chromatography and the required product was eluted in a solvent mixture (hexane:EtOAc, 80:20, v/v) as an off white solid with $65 \%$ yield. ${ }^{1} \mathrm{H}-\mathrm{NMR}$ data $\left(500 \mathrm{MHz}, \mathrm{CDCl}_{3}\right): \delta(\mathrm{ppm})=10.84(\mathrm{~s},-\mathrm{CH}=\mathrm{N}-, 1 \mathrm{H})$, 6.78-6.81 (m, Ar-H, 2H), 5.76-5.84 (m, $-\mathrm{CH}=\mathrm{CH}_{2}-$, $1 \mathrm{H}), \quad 4.91-5.00 \quad\left(\mathrm{~m}, \quad-\mathrm{CH}=\mathrm{CH}_{2}-, \quad 2 \mathrm{H}\right), \quad 2.77-2.80$ (t, $\left.-\mathrm{CH}_{2}-, J=7.4 \mathrm{~Hz}, 2 \mathrm{H}\right), 2.00-2.05\left(\mathrm{~m},-\mathrm{CH}_{2}-, 2 \mathrm{H}\right)$, 1.70-1.76 (m, $\left.-\mathrm{CH}_{2}-, 2 \mathrm{H}\right), 1.25-1.41\left(\mathrm{~m},-\left(\mathrm{CH}_{2}\right)_{5}^{-}\right.$, $10 \mathrm{H}) ;{ }^{13} \mathrm{C}$ NMR $\left(100 \mathrm{MHz}, \mathrm{CDCl}_{3}\right): \delta(\mathrm{ppm})=165.8$, 163.9, 163.1, 161.9, 161.0, 153.2, 150.3, 139.1, 114.1, 107.7, 101.3, 33.7, 31.8, 29.2, 29.0, 28.8, 25.9, 25.0, 22.6; IR $\left(\mathrm{CHCl}_{3} v_{\max } \mathrm{cm}^{-1}\right): 3409,3071,2922,2852$, $1640,1596,1442$, 1349, 1276, 1175, 1125, 1050, 847, 746.

4-((4-Bromobenzylidene)amino)-5-(dec-9-en-1-yl)4H-1,2,4-triazole-3-thiol (6g):

The crude compound was subjected to silica gel column chromatography and the required product was eluted in a solvent mixture (hexane:EtOAc, 75:25, v/v) as an off white solid with $69 \%$ yield. ${ }^{1} \mathrm{H}-\mathrm{NMR}$ data $(500 \mathrm{MHz}$, $\left.\mathrm{CDCl}_{3}\right): \delta(\mathrm{ppm})=10.49(\mathrm{~s},-\mathrm{CH}=\mathrm{N}-, 1 \mathrm{H}), 7.73(\mathrm{~d}$, Ar$\mathrm{H}, J=8.5 \mathrm{~Hz}, 1 \mathrm{H}), 7.63$ (d, Ar-H, $J=8.5 \mathrm{~Hz}, 1 \mathrm{H}), 5.77$ $5.84\left(\mathrm{~m},-\mathrm{CH}=\mathrm{CH}_{2}-, 1 \mathrm{H}\right), 4.92-5.00\left(\mathrm{~m},-\mathrm{CH}=\mathrm{CH}_{2}-\right.$, $2 \mathrm{H}), 2.79-2.82\left(\mathrm{t},-\mathrm{CH}_{2}-, J=7.4 \mathrm{~Hz}, 2 \mathrm{H}\right), 2.00-2.04$ (m, $\left.-\mathrm{CH}_{2}-, 2 \mathrm{H}\right), 1.72-1.78\left(\mathrm{~m},-\mathrm{CH}_{2}-, 2 \mathrm{H}\right), 1.25-1.45$ (m, $\left.\left.-\left(\mathrm{CH}_{2}\right)_{5}-, 10 \mathrm{H}\right) ;{ }^{13} \mathrm{C} \mathrm{NMR} \mathrm{(125} \mathrm{MHz,} \mathrm{CDCl}_{3}\right)$ : $\delta(\mathrm{ppm})=162.0,159.1,152.9,139.0,132.2,131.5$, 129.9, 127.0, 114.1, 33.7, 31.8, 29.2, 29.0, 28.8, 25.9, 25.0, 22.6; IR $\left(\mathrm{CHCl}_{3} v_{\max } \mathrm{cm}^{-1}\right): 3406,3109,3062$, 2923, 2853, 1589, 148, 1418, 1283, 1172, 1070, 1011. 820; ESI-MS: $m / z$ at $421[\mathrm{M}-\mathrm{H}]^{+}$.

\section{2-(((3-(Dec-9-en-1-yl)-5-mercapto-4H-1,2,4-triazol- 4-yl)imino)methyl)phenol (6h):}

The crude compound was subjected to silica gel column chromatography and the required product was eluted in a solvent mixture (hexane:EtOAc, 70:30, v/v) as an off white semi solid with $74 \%$ yield. ${ }^{1} \mathrm{H}-\mathrm{NMR}$ data $\left(500 \mathrm{MHz}, \mathrm{CDCl}_{3}\right): \delta(\mathrm{ppm})=10.27(\mathrm{~s},-\mathrm{CH}=\mathrm{N}-$, 1H), 7.43-7.48 (m, Ar-H, 2H), 7.00-7.06 (m, Ar-H, $2 \mathrm{H})$, 5.75-5.84 (m, $\left.-\mathrm{CH}=\mathrm{CH}_{2}-, 1 \mathrm{H}\right), 4.91-5.00(\mathrm{~m}$,
$\left.-\mathrm{CH}=\mathrm{CH}_{2}-, 2 \mathrm{H}\right), 2.75-2.78\left(\mathrm{t},-\mathrm{CH}_{2}-, J=7.4 \mathrm{~Hz}, 2 \mathrm{H}\right)$, 2.00-2.04 (m, $\left.-\mathrm{CH}_{2}-, 2 \mathrm{H}\right), 1.72-1.78\left(\mathrm{~m},-\mathrm{CH}_{2}-, 2 \mathrm{H}\right)$, 1.25-1.41 (m, $\left.-\left(\mathrm{CH}_{2}\right)_{5}-, 10 \mathrm{H}\right) ;{ }^{13} \mathrm{C} \mathrm{NMR} \mathrm{(125} \mathrm{MHz,}$ $\left.\mathrm{CDCl}_{3}\right): \delta(\mathrm{ppm})=166.0,162.3,159.7,151.5,139.0$, 134.6, 133.5, 120.1, 117.4, 116.0, 114.1, 33.7, 31.8, 29.1, 28.9, 28.8, 25.8, 25.1, 22.6; IR $\left(\mathrm{CHCl}_{3} v_{\max } \mathrm{cm}^{-1}\right)$ : 3401, 2924, 2853, 2108, 1605, 1464, 1297, 1153, 756; HR-MS (ESI) $m / z$ [M-H']: 357.22718.

\section{4-((4-Chlorobenzylidene)amino)-5-(dec-9-en-1-yl)-} 4H-1,2,4-triazole-3-thiol (6i):

The crude compound was subjected to silica gel column chromatography and the required product was eluted in a solvent mixture (hexane:EtOAc, 75:25, v/v) as an off white solid with $79 \%$ yield. ${ }^{1} \mathrm{H}-\mathrm{NMR}$ data $\left(400 \mathrm{MHz}, \mathrm{CDCl}_{3}\right): \delta(\mathrm{ppm})=10.47(\mathrm{~s},-\mathrm{CH}=\mathrm{N}-, 1 \mathrm{H})$, 7.81 (d, Ar-H, $J=8.5 \mathrm{~Hz}, 2 \mathrm{H}), 7.47$ (d, Ar-H, $J=8.5$ $\mathrm{Hz}, 2 \mathrm{H}), 5.74-5.84\left(\mathrm{~m},-\mathrm{CH}=\mathrm{CH}_{2}-, 1 \mathrm{H}\right), 4.91-5.01$ (m, $\left.-\mathrm{CH}=\mathrm{CH}_{2}-, 2 \mathrm{H}\right), 2.79-2.83\left(\mathrm{t},-\mathrm{CH}_{2}^{-}, J=7.4 \mathrm{~Hz}, 2 \mathrm{H}\right)$, 2.00-2.05 (m, $\left.-\mathrm{CH}_{2}-, 2 \mathrm{H}\right), 1.71-1.79\left(\mathrm{~m},-\mathrm{CH}_{2}^{-}, 2 \mathrm{H}\right)$, 1.25-1.41 (m, $\left.-\left(\mathrm{CH}_{2}\right)_{5}-, 10 \mathrm{H}\right) ;{ }^{13} \mathrm{C} \mathrm{NMR}(100 \mathrm{MHz}$, $\left.\mathrm{CDCl}_{3}\right): \delta(\mathrm{ppm})=161.7,159.2,152.8,139.0,138.4$, 131.0, 129.7, 129.2, 114.1, 33.7, 31.8, 29.2, 28.9, 28.8, 25.9, 25.0, 22.6; IR $\left(\mathrm{CHCl}_{3} v_{\max } \mathrm{cm}^{-1}\right): 3156,2925$, 2854, 1591, 1472, 1278, 1089, 1014, 825, 516; HR-MS (ESI) $m / z\left[\mathrm{M}+\mathrm{H}^{+}\right]$: calc for $\mathrm{C}_{19} \mathrm{H}_{26} \mathrm{~N}_{4} \mathrm{ClS}$ is 377.15612 found $377.15589\left(\mathrm{C}_{19} \mathrm{H}_{26} \mathrm{~N}_{4} \mathrm{ClS}\right)$.

\section{4-((3-Bromo-4-methoxybenzylidene)amino)-5-(dec- 9-en-1-yl)-4H-1,2,4-triazole-3-thiol (6j):}

The crude compound was subjected to silica gel column chromatography and the required product was eluted in a solvent mixture (hexane:EtOAc, 75:25, v/v) as an off white solid with $68 \%$ yield. ${ }^{1} \mathrm{H}-\mathrm{NMR}$ data $(500 \mathrm{MHz}$, $\left.\mathrm{CDCl}_{3}\right): \delta(\mathrm{ppm})=10.27(\mathrm{~s},-\mathrm{CH}=\mathrm{N}-, 1 \mathrm{H}), 8.12(\mathrm{~d}, \mathrm{Ar}-$ $\mathrm{H}, J=1.9 \mathrm{~Hz}, 1 \mathrm{H}), 7.72-7.74$ (m, Ar-H, 1H), 6.98 (m, $\mathrm{Ar}-\mathrm{H}, 1 \mathrm{H}), 5.75-5.83\left(\mathrm{~m},-\mathrm{CH}=\mathrm{CH}_{2}-, 1 \mathrm{H}\right), 4.91-5.00$ $\left(\mathrm{m},-\mathrm{CH}=\mathrm{CH}_{2}-, 2 \mathrm{H}\right), 3.98\left(\mathrm{~m}, \mathrm{OCH}_{3}, 3 \mathrm{H}\right), 2.79-2.82$ (t, $\left.-\mathrm{CH}_{2}-, J=7.4 \mathrm{~Hz}, 2 \mathrm{H}\right), 2.00-2.04\left(\mathrm{~m},-\mathrm{CH}_{2}-, 2 \mathrm{H}\right)$, 1.73-1.78 (m, $\left.-\mathrm{CH}_{2}-, 2 \mathrm{H}\right), 1.25-1.41\left(\mathrm{~m},-\left(\mathrm{CH}_{2}\right)_{5}-, 10 \mathrm{H}\right)$; ${ }^{13} \mathrm{C}$ NMR $\left(125 \mathrm{MHz}, \mathrm{CDCl}_{3}\right): \delta(\mathrm{ppm})=161.8,159.2$, 159.0, 152.8, 139.0, 132.7, 130.2, 126.3, 114.1, 112.6, 111.6, 56.4, 33.7, 31.8, 29.2, 29.0, 28.8, 25.9, 25.0, 22.6; IR $\left(\mathrm{CHCl}_{3} v_{\max } \mathrm{cm}^{-1}\right): 3381,2922,2852,2109$, 1591, 1497, 1469, 1415, 1265, 1160, 1050, 1018, 914, 804, 771, 577; ESI-MS: $m / z$ at $451[\mathrm{M}+\mathrm{H}]^{+}$.

\section{5-(Dec-9-en-1-yl)-4-((3-fluorobenzylidene)amino)- 4H-1,2,4-triazole-3-thiol (6k):}

The crude compound was subjected to silica gel column chromatography and the required product was eluted in 
a solvent mixture (hexane:EtOAc, 75:25, v/v) as an off white solid with $79 \%$ yield. ${ }^{1} \mathrm{H}-\mathrm{NMR}$ data $(500 \mathrm{MHz}$, $\left.\mathrm{CDCl}_{3}\right): \delta(\mathrm{ppm})=10.56(\mathrm{~s},-\mathrm{CH}=\mathrm{N}-, 1 \mathrm{H}), 7.58-7.62$ (m, Ar-H, 2H), 7.44-7.48 (m, Ar-H, 1H), 7.22-7.25 $(\mathrm{m}, \mathrm{Ar}-\mathrm{H}, 1 \mathrm{H}), \quad 5.75-5.84 \quad\left(\mathrm{~m},-\mathrm{CH}=\mathrm{CH}_{2}-, 1 \mathrm{H}\right)$, 4.91-5.00 (m, $\left.-\mathrm{CH}=\mathrm{CH}_{2}-, 2 \mathrm{H}\right), 2.80-2.82\left(\mathrm{t},-\mathrm{CH}_{2}-\right.$, $J=7.4 \mathrm{~Hz}, 2 \mathrm{H}), 2.00-2.04\left(\mathrm{~m},-\mathrm{CH}_{2}-, 2 \mathrm{H}\right), 1.73-1.79$ $\left(\mathrm{m},-\mathrm{CH}_{2}-, 2 \mathrm{H}\right), 1.24-1.42\left(\mathrm{~m},-\left(\mathrm{CH}_{2}\right)_{5}-, 10 \mathrm{H}\right) ;{ }^{13} \mathrm{C}$ NMR $\left(100 \mathrm{MHz}, \mathrm{CDCl}_{3}\right): \delta(\mathrm{ppm})=164.2,162.1$, 158.7, 153.0, 139.1, 134.8, 130.6, 125.2, 119.4, 114.2, 114.1, 33.7, 31.8, 29.2, 29.0, 28.8, 25.9, 25.0, 22.6; IR $\left(\mathrm{CHCl}_{3} v_{\max } \mathrm{cm}^{-1}\right): 3406,3148,2921,2853,1612,1578$, 1496, 1414, 128, 1266, 1159, 1001, 906. 786; HR-MS (ESI) $m / z\left[\mathrm{M}+\mathrm{H}^{+}\right]$: calc for $\mathrm{C}_{19} \mathrm{H}_{26} \mathrm{~N}_{4} \mathrm{FS}$ is 361.18567 found $361.18475\left(\mathrm{C}_{19} \mathrm{H}_{26} \mathrm{~N}_{4} \mathrm{FS}\right)$.

4-((2-Bromobenzylidene)amino)-5-(dec-9-en-1-yl)4H-1,2,4-triazole-3-thiol (61):

The crude compound was subjected to silica gel column chromatography and the required product was eluted in a solvent mixture (hexane:EtOAc, 75:25, $\mathrm{v} / \mathrm{v})$ as an off white solid with $81 \%$ yield. ${ }^{1} \mathrm{H}-\mathrm{NMR}$ data $\left(500 \mathrm{MHz}, \mathrm{CDCl}_{3}\right): \delta(\mathrm{ppm})=10.97(\mathrm{~s},-\mathrm{CH}=\mathrm{N}-$, 1H), 8.10 (d, Ar-H, J=8.3 Hz, 1H), 7.68 (d, Ar-H, $J=9.1 \mathrm{~Hz}, 1 \mathrm{H}), 7.35-7.43$ (m, Ar-H, 2H), 5.75-5.84 (m, $\left.-\mathrm{CH}=\mathrm{CH}_{2}-, 1 \mathrm{H}\right), 4.91-5.00\left(\mathrm{~m},-\mathrm{CH}=\mathrm{CH}_{2}^{-}, 2 \mathrm{H}\right), 2.81-$ $2.84\left(\mathrm{t},-\mathrm{CH}_{2}^{-}, J=7.4 \mathrm{~Hz}, 2 \mathrm{H}\right), 2.00-2.04\left(\mathrm{~m},-\mathrm{CH}_{2}^{-}\right.$, $2 \mathrm{H}), 1.73-1.79\left(\mathrm{~m},-\mathrm{CH}_{2^{-}}, 2 \mathrm{H}\right), 1.25-1.43\left(\mathrm{~m},-\left(\mathrm{CH}_{2}\right)_{5}^{-}\right.$, $10 \mathrm{H}) ;{ }^{13} \mathrm{C}$ NMR $\left(100 \mathrm{MHz}, \mathrm{CDCl}_{3}\right): \delta(\mathrm{ppm})=161.9$, 159.2, 152.9, 139.0, 133.4, 133.1, 132.2, 127.9, 127.6, 126.4, 114.1, 33.7, 31.8, 29.2, 28.9, 28.8, 25.9, 25.0; IR $\left(\mathrm{CHCl}_{3} v_{\max } \mathrm{cm}^{-1}\right): 3149,2925,2853,1639,1585,1465$, 1416, 1355, 1277, 1122, 1024, 909, 756; HR-MS (ESI) $m / z\left[\mathrm{M}+\mathrm{H}^{+}\right]$: calc for $\mathrm{C}_{19} \mathrm{H}_{26} \mathrm{~N}_{4} \mathrm{BrS}$ is 421.10561 found $421.10510\left(\mathrm{C}_{19} \mathrm{H}_{26} \mathrm{~N}_{4} \mathrm{BrS}\right)$.

\section{5-(Dec-9-en-1-yl)-4-((2-methoxybenzylidene)amino) $-4 \mathrm{H}-1,2,4-$ triazole-3-thiol $(6 \mathrm{~m})$ :}

The crude compound was subjected to silica gel column chromatography and the required product was eluted in a solvent mixture (hexane:EtOAc, 75:25, v/v) as an off white solid with $86 \%$ yield. ${ }^{1} \mathrm{H}-\mathrm{NMR}$ data (500 $\left.\mathrm{MHz}, \mathrm{CDCl}_{3}\right): \delta(\mathrm{ppm})=10.75(\mathrm{~s},--\mathrm{SH}, 1 \mathrm{H}), 10.50$ $(\mathrm{s},-\mathrm{CH}=\mathrm{N}-, 1 \mathrm{H}), 8.06(\mathrm{dd}, \mathrm{Ar}-\mathrm{H}, 1 \mathrm{H}), 7.48-7.51$ (t, Ar-H, 1H), 7.02-7.05 (t, Ar-H, 1H), 6.98 (d, Ar-H, $J=8.3 \mathrm{~Hz}, 1 \mathrm{H}), 5.75-5.84\left(\mathrm{~m},-\mathrm{CH}=\mathrm{CH}_{2}-, 1 \mathrm{H}\right), 4.90-5.00$ $\left(\mathrm{m},-\mathrm{CH}=\mathrm{CH}_{2}-, 2 \mathrm{H}\right), 3.91\left(\mathrm{~s},-\mathrm{OCH}_{3}, 3 \mathrm{H}\right), 2.77-2.81$ (t, $\left.-\mathrm{CH}_{2}-, J=7.4 \mathrm{~Hz}, 2 \mathrm{H}\right), 2.00-2.04\left(\mathrm{~m},-\mathrm{CH}_{2}-, 2 \mathrm{H}\right)$, 1.73-1.77 (m, $\left.-\mathrm{CH}_{2}-, 2 \mathrm{H}\right), 1.25-1.40\left(\mathrm{~m},-\left(\mathrm{CH}_{2}\right)_{5}-, 10 \mathrm{H}\right)$; ${ }^{13} \mathrm{C}$ NMR $\left(125 \mathrm{MHz}, \mathrm{CDCl}_{3}\right): \delta(\mathrm{ppm})=161.8,159.6$,
158.7, 152.6, 139.0, 133.9, 126.9, 121.0, 120.7, 114.0, 111.4, 55.8, 33.7, 29.6, 29.2, 28.9, 28.8, 25.9, 25.0; IR $\left(\mathrm{CHCl}_{3} v_{\max } \mathrm{cm}^{-1}\right): 3344,2926,2853,2108,1682,1589$, 1456, 1284, 1166, 997, 874, 785, 683; HR-MS (ESI) $m / z\left[\mathrm{M}+\mathrm{H}^{+}\right]$: calc for $\mathrm{C}_{20} \mathrm{H}_{29} \mathrm{~N}_{4} \mathrm{OS}$ is 373.20566 found $373.20474\left(\mathrm{C}_{20} \mathrm{H}_{29} \mathrm{~N}_{4} \mathrm{OS}\right)$.

\section{5-(Dec-9-en-1-yl)-4-((4-fluorobenzylidene)amino)- 4H-1,2,4-triazole-3-thiol (6n):}

The crude compound was subjected to silica gel column chromatography and the required product was eluted in a solvent mixture (hexane:EtOAc, 75: 25, v/v) as an off white solid with $72 \%$ yield. ${ }^{1} \mathrm{H}-\mathrm{NMR}$ data $(500 \mathrm{MHz}$, $\left.\mathrm{CDCl}_{3}\right): \delta(\mathrm{ppm})=10.69(\mathrm{~s},-\mathrm{SH}, 1 \mathrm{H}), 10.40(\mathrm{~s},-\mathrm{CH}=\mathrm{N}-$, 1H), 7.89 (d, Ar-H, $J=8.5 \mathrm{~Hz}, 2 \mathrm{H}$ ), 7.19 (d, Ar-H, $J=8.5$ $\mathrm{Hz}, 2 \mathrm{H}), 5.75-5.83\left(\mathrm{~m},-\mathrm{CH}=\mathrm{CH}_{2}-, 1 \mathrm{H}\right), 4.91-5.00$ (m, $\left.-\mathrm{CH}=\mathrm{CH}_{2}-, 2 \mathrm{H}\right), 2.79-2.82\left(\mathrm{t},-\mathrm{CH}_{2}-, J=7.4 \mathrm{~Hz}\right.$, $2 \mathrm{H}), 2.00-2.04\left(\mathrm{~m},-\mathrm{CH}_{2}-, 2 \mathrm{H}\right), 1.72-1.78\left(\mathrm{~m},-\mathrm{CH}_{2}-\right.$ , 2H), 1.25-1.41 (m, $\left.-\left(\mathrm{CH}_{2}\right)_{5}-, 10 \mathrm{H}\right) ;{ }^{13} \mathrm{C}$ NMR (100 $\left.\mathrm{MHz}, \mathrm{CDCl}_{3}\right): \delta(\mathrm{ppm})=164.0,161.9,159.6,152.9$, 139.0, 130.8, 128.8, 116.3, 114.1, 33.7, 31.8, 29.2, 29.0, 28.8, 25.9, 25.0, 22.6; IR $\left(\mathrm{CHCl}_{3} v_{\max } \mathrm{cm}^{-1}\right)$ : 3392, 2927, 2855, 2108, 1603, 1511, 1466, 1413, 1277, 1235, 1154, 910. 837; HR-MS (ESI) $m / z\left[\mathrm{M}+\mathrm{H}^{+}\right]$: calc for $\mathrm{C}_{19} \mathrm{H}_{26} \mathrm{~N}_{4} \mathrm{FS}$ is 361.18567 found 361.18476 $\left(\mathrm{C}_{19} \mathrm{H}_{26} \mathrm{~N}_{4} \mathrm{FS}\right)$.

\section{4-((5-Chloro-2-nitrobenzylidene)amino)-5-(dec-9- en-1-yl)-4H-1,2,4-triazole-3-thiol (6o):}

The crude compound was subjected to silica gel column chromatography and the required product was eluted in a solvent mixture (hexane:EtOAc, 75:25, v/v) as a light yellow solid with $71 \%$ yield. ${ }^{1} \mathrm{H}-\mathrm{NMR}$ data $(500 \mathrm{MHz}$, $\left.\mathrm{CDCl}_{3}\right): \delta(\mathrm{ppm})=11.20(\mathrm{~s},-\mathrm{SH}, 1 \mathrm{H}), 10.17(\mathrm{~s},-\mathrm{CH}=\mathrm{N}-$, 1H), 8.13 (d, Ar-H, J=8.6 Hz, 1H), 8.05 (s, Ar-H, 1H), 7.65 (m, Ar-H, 1H), 5.76-5.83 (m, $-\mathrm{CH}=\mathrm{CH}_{2}-$, $1 \mathrm{H}), \quad 4.91-5.00 \quad\left(\mathrm{~m}, \quad-\mathrm{CH}=\mathrm{CH}_{2}-, \quad 2 \mathrm{H}\right), \quad 2.79-2.82$ (t, $\left.-\mathrm{CH}_{2}-, J=7.4 \mathrm{~Hz}, 2 \mathrm{H}\right), 2.00-2.04\left(\mathrm{~m},-\mathrm{CH}_{2}-, 2 \mathrm{H}\right)$, $1.72-1.78\left(\mathrm{~m},-\mathrm{CH}_{2}-, 2 \mathrm{H}\right), 1.25-1.42\left(\mathrm{~m},-\left(\mathrm{CH}_{2}\right)_{5}-, 10 \mathrm{H}\right)$; ${ }^{13} \mathrm{C}$ NMR $\left(125 \mathrm{MHz}, \mathrm{CDCl}_{3}\right): \delta(\mathrm{ppm})=162.3,155.2$, $152.9,146.7,140.4,139.0,131.8,129.9,129.2,126.4$, 114.1, 33.7, 31.8, 29.2, 28.9, 28.8, 25.9, 24.9, 22.6; IR $\left(\mathrm{CHCl}_{3} v_{\max } \mathrm{cm}^{-1}\right): 3404,2926,2854,2108,1563,1528$, 1465, 1414, 1341, 1270, 1109, 854; HR-MS (ESI) $\mathrm{m} / \mathrm{z}$ $\left[\mathrm{M}+\mathrm{H}^{+}\right]$: calc for $\mathrm{C}_{19} \mathrm{H}_{25} \mathrm{O}_{2} \mathrm{~N}_{5} \mathrm{ClS}$ is 422.14120 found $422.13967\left(\mathrm{C}_{19} \mathrm{H}_{25} \mathrm{O}_{2} \mathrm{~N}_{5} \mathrm{ClS}\right)$.

5-(Dec-9-en-1-yl)-4-((2-nitrobenzylidene)amino)4H-1,2,4-triazole-3-thiol (6p):

The crude compound was subjected to silica gel column 
chromatography and the required product was eluted in a solvent mixture (hexane:EtOAc, 75:25, v/v) as a light yellow solid with $68 \%$ yield. ${ }^{1} \mathrm{H}-\mathrm{NMR}$ data $(400 \mathrm{MHz}$, $\left.\mathrm{CDCl}_{3}\right): \delta(\mathrm{ppm})=11.04(\mathrm{~s},-\mathrm{SH}, 1 \mathrm{H}), 10.64(\mathrm{~s},-\mathrm{CH}=\mathrm{N}-$, $1 \mathrm{H})$, 8.08-8.14 (m, Ar-H, 2H), 7.67-7.78 (m, Ar-H, $2 \mathrm{H})$, 5.75-5.84 (m, $\left.-\mathrm{CH}=\mathrm{CH}_{2}-, 1 \mathrm{H}\right), 4.91-5.00(\mathrm{~m}$, $\left.-\mathrm{CH}=\mathrm{CH}_{2}-, 2 \mathrm{H}\right), 2.78-2.80\left(\mathrm{t},-\mathrm{CH}_{2}-, J=7.4 \mathrm{~Hz}, 2 \mathrm{H}\right)$, 1.99-2.05 (m, $\left.-\mathrm{CH}_{2}-, 2 \mathrm{H}\right), 1.71-1.79\left(\mathrm{~m},-\mathrm{CH}_{2}-, 2 \mathrm{H}\right)$, 1.24-1.41 (m, $\left.-\left(\mathrm{CH}_{2}\right)_{5}-, 10 \mathrm{H}\right) ;{ }^{13} \mathrm{C}$ NMR $(125 \mathrm{MHz}$, $\left.\mathrm{CDCl}_{3}\right): \delta(\mathrm{ppm})=162.1,157.2,152.8,148.6,139.0$, 133.6, 132.0, 129.6, 127.9, 124.8, 114.0, 33.6, 31.8, 29.1, 28.9, 28.7, 25.9, 24.9, 22.6; IR $\left(\mathrm{CHCl}_{3} v_{\max } \mathrm{cm}^{-1}\right)$ : 3110, 3066, 2927, 2855, 1640, 1585, 1528, 1413, 1347, 1280, 1169, 996, 854, 737; HR-MS (ESI) $m / z$ [M+H']: calc for $\mathrm{C}_{19} \mathrm{H}_{26} \mathrm{O}_{2} \mathrm{~N}_{5} \mathrm{~S}$ is 388.18017 found 388.17932 $\left(\mathrm{C}_{19} \mathrm{H}_{26} \mathrm{O}_{2} \mathrm{~N}_{5} \mathrm{~S}\right)$.

\section{5-(Dec-9-en-1-yl)-4-((2-fluorobenzylidene)amino)- 4H-1,2,4-triazole-3-thiol (6q):}

The crude compound was subjected to silica gel column chromatography and the required product was eluted in a solvent mixture (hexane:EtOAc, 75:25, v/v) as an off white solid with $64 \%$ yield. ${ }^{1} \mathrm{H}-\mathrm{NMR}$ data $\left(500 \mathrm{MHz}, \mathrm{CDCl}_{3}\right): \delta(\mathrm{ppm})=10.72(\mathrm{~s},-\mathrm{CH}=\mathrm{N}-, 1 \mathrm{H})$, 8.06 (t, Ar-H, 1H), 7.50-7.54 (m, Ar-H, 1H), 7.24-7.27 (t, Ar-H, 1H), 7.17-7.19 (t, Ar-H, 1H), 5.77-5.83 (m, $\left.-\mathrm{CH}=\mathrm{CH}_{2}-, 1 \mathrm{H}\right), 4.91-4.99\left(\mathrm{~m},-\mathrm{CH}=\mathrm{CH}_{2}-, 2 \mathrm{H}\right), 2.80-$ $2.83\left(\mathrm{t},-\mathrm{CH}_{2}-, J=7.4 \mathrm{~Hz}, 2 \mathrm{H}\right), 2.00-2.04\left(\mathrm{~m},-\mathrm{CH}_{2}-\right.$, $2 \mathrm{H}), 1.73-1.79\left(\mathrm{~m},-\mathrm{CH}_{2}-, 2 \mathrm{H}\right), 1.25-1.40\left(\mathrm{~m},-\left(\mathrm{CH}_{2}\right)_{5}^{-}\right.$, $10 \mathrm{H}) ;{ }^{13} \mathrm{C}$ NMR $\left(100 \mathrm{MHz}, \mathrm{CDCl}_{3}\right): \delta(\mathrm{ppm})=163.7$, 162.0, 154.5, 152.9, 139.0, 134.1, 127.3, 124.5, 120.7, $116.3,114.1,33.7,31.8,29.2,29.0,28.8,25.9,25.0$, 22.6; IR $\left(\mathrm{CHCl}_{3} v_{\max } \mathrm{cm}^{-1}\right): 3409,3107,2924,2852$, 2108, 1613, 1582, 1415, 1285, 1101, 876, 764; HR-MS (ESI) $m / z\left[\mathrm{M}+\mathrm{H}^{+}\right]$: calc for $\mathrm{C}_{19} \mathrm{H}_{26} \mathrm{~N}_{4} \mathrm{~S}$ is 361.18567 found $361.18476\left(\mathrm{C}_{19} \mathrm{H}_{26} \mathrm{~N}_{4} \mathrm{~S}\right)$.

\section{5-(Dec-9-en-1-yl)-4-((3-(trifluoromethoxy) benzylidene)amino)-4H-1,2,4-triazole-3-thiol (6r):}

The crude compound was subjected to silica gel column chromatography and the required product was eluted in a solvent mixture (hexane:EtOAc, 75:25, v/v) as an off white solid with $72 \%$ yield. ${ }^{1} \mathrm{H}-\mathrm{NMR}$ data $\left(300 \mathrm{MHz}, \mathrm{CDCl}_{3}\right): \delta(\mathrm{ppm})=13.56(\mathrm{~s},-\mathrm{SH}, 1 \mathrm{H}), 10.60$ $(\mathrm{s},-\mathrm{CH}=\mathrm{N}-, 1 \mathrm{H}), 7.74-7.80(\mathrm{~m}, \mathrm{Ar}-\mathrm{H}, 2 \mathrm{H}), 7.60$ (d, Ar$\mathrm{H}, J=9.1 \mathrm{~Hz}, 1 \mathrm{H}), 7.38-7.54$ (m, Ar-H, 2H), 5.71-5.84 (m, $\left.-\mathrm{CH}=\mathrm{CH}_{2}-, 1 \mathrm{H}\right), 4.89-4.99\left(\mathrm{~m},-\mathrm{CH}=\mathrm{CH}_{2}-, 2 \mathrm{H}\right)$, 2.80-2.82 (t, $\left.-\mathrm{CH}_{2^{-}}, J=7.4 \mathrm{~Hz}, 2 \mathrm{H}\right), 2.00-2.04\left(\mathrm{~m},-\mathrm{CH}_{2}-\right.$, $2 \mathrm{H}), 1.69-1.79\left(\mathrm{~m},-\mathrm{CH}_{2}^{-}, 2 \mathrm{H}\right), 1.25-1.43\left(\mathrm{~m},-\left(\mathrm{CH}_{2}\right)_{5}-\right.$, $10 \mathrm{H}) ;{ }^{13} \mathrm{C}$ NMR $\left(75 \mathrm{MHz}, \mathrm{CDCl}_{3}\right): \delta(\mathrm{ppm})=160.1$,
$156.9,150.4,147.8,137.3,133.5,129.6,129.4,126.1$, 122.8, 118.0, 112.8, 32.0, 30.1, 27.5, 27.2, 27.1, 24.4, 23.3, 20.9; IR $\left(\mathrm{CHCl}_{3} v_{\max } \mathrm{cm}^{-1}\right): 3425,2927,2254$, 2128, 1650, 1415, 1257, 1217, 1163, 1026, 1005, 825, 764; HR-MS (ESI) $m / z\left[\mathrm{M}+\mathrm{H}^{+}\right]$: calc for $\mathrm{C}_{20} \mathrm{H}_{26} \mathrm{ON}_{4} \mathrm{~F}_{3} \mathrm{~S}$ is 427.17739 found $427.17586\left(\mathrm{C}_{20} \mathrm{H}_{26} \mathrm{ON}_{4} \mathrm{~F}_{3} \mathrm{~S}\right)$.

\section{5-(Dec-9-en-1-yl)-4-((5-fluoro-2-nitrobenzylidene) amino)-4H-1,2,4-triazole-3-thiol (6s):}

The crude compound was subjected to silica gel column chromatography and the required product was eluted in a solvent mixture (hexane:EtOAc, 75:25, v/v) as a light yellow solid with $75 \%$ yield. ${ }^{1} \mathrm{H}-\mathrm{NMR}$ data $\left(500 \mathrm{MHz}, \mathrm{CDCl}_{3}\right): \delta(\mathrm{ppm})=11.23(\mathrm{~s},-\mathrm{SH}, 1 \mathrm{H}), 10.88$ $(\mathrm{s},-\mathrm{CH}=\mathrm{N}-, 1 \mathrm{H}), 8.21-8.24$ (m, Ar-H, 1H), 7.77-7.79 (m, Ar-H, 1H), 7.34-7.38 (m, Ar-H, 1H), 5.75-5.83 (m, $\left.-\mathrm{CH}=\mathrm{CH}_{2}-, 1 \mathrm{H}\right), 4.90-5.00\left(\mathrm{~m},-\mathrm{CH}=\mathrm{CH}_{2}-, 2 \mathrm{H}\right)$, 2.80-2.83 (t, $\left.-\mathrm{CH}_{2}-, J=7.4 \mathrm{~Hz}, 2 \mathrm{H}\right), 2.00-2.04\left(\mathrm{~m},-\mathrm{CH}_{2}-\right.$, $2 \mathrm{H}), 1.73-1.79\left(\mathrm{~m},-\mathrm{CH}_{2}-, 2 \mathrm{H}\right), 1.24-1.43\left(\mathrm{~m},-\left(\mathrm{CH}_{2}\right)_{5}-\right.$, $10 \mathrm{H}) ;{ }^{13} \mathrm{C}$ NMR $\left(125 \mathrm{MHz}, \mathrm{CDCl}_{3}\right): \delta(\mathrm{ppm})=165.8$, $163.8,162.3,155.1,152.9,144.7,139.0,128.0,118.9$, 116.1, 114.1, 33.7, 31.8, 29.2, 28.9, 28.8, 25.9, 24.9, 22.6; IR $\left(\mathrm{CHCl}_{3} v_{\max } \mathrm{cm}^{-1}\right): 3147,2926,2854,1577$, 1529, 1471, 1422, 1344, 1277, 1161, 856, 753; HR-MS (ESI) $m / z\left[\mathrm{M}+\mathrm{H}^{+}\right]$: calc for $\mathrm{C}_{19} \mathrm{H}_{25} \mathrm{O}_{2} \mathrm{~N}_{5} \mathrm{FS}$ is 406.17075 found $406.16944\left(\mathrm{C}_{19} \mathrm{H}_{25} \mathrm{O}_{2} \mathrm{~N}_{5} \mathrm{FS}\right)$.

\section{5-(Dec-9-en-1-yl)-4-((3-methoxybenzylidene)amino) $-4 H-1,2,4-$ triazole-3-thiol (6t):}

The crude compound was subjected to silica gel column chromatography and the required product was eluted in a solvent mixture (hexane:EtOAc, 75:25, v/v) as an off white solid with $83 \%$ yield. ${ }^{1} \mathrm{H}-\mathrm{NMR}$ data $\left(500 \mathrm{MHz}, \mathrm{CDCl}_{3}\right): \delta(\mathrm{ppm})=10.84(\mathrm{~s},-\mathrm{SH}, 1 \mathrm{H}), 10.35$ $(\mathrm{s},-\mathrm{CH}=\mathrm{N}-, 1 \mathrm{H}), 7.38-7.43$ (m, Ar-H, 3H), 7.07-7.10 (m, Ar-H, $1 \mathrm{H}), 5.75-5.83\left(\mathrm{~m},-\mathrm{CH}=\mathrm{CH}_{2}-1 \mathrm{H}\right), 4.91-$ $5.00\left(\mathrm{~m},-\mathrm{CH}=\mathrm{CH}_{2}-, 2 \mathrm{H}\right), 3.87\left(\mathrm{~s},-\mathrm{OCH}_{3}, 3 \mathrm{H}\right), 2.80-$ $2.83\left(\mathrm{t},-\mathrm{CH}_{2}-, J=7.4 \mathrm{~Hz}, 2 \mathrm{H}\right), 2.00-2.04\left(\mathrm{~m},-\mathrm{CH}_{2}-\right.$, $2 \mathrm{H}), 1.73-1.79\left(\mathrm{~m},-\mathrm{CH}_{2}^{-}, 2 \mathrm{H}\right), 1.25-1.42\left(\mathrm{~m},-\left(\mathrm{CH}_{2}\right)_{5}^{-}\right.$, $10 \mathrm{H}) ;{ }^{13} \mathrm{C}$ NMR $\left(100 \mathrm{MHz}, \mathrm{CDCl}_{3}\right): \delta(\mathrm{ppm})=161.8$, 161.0, 159.8, 152.8, 139.0, 133.8, 129.9, 121.8, 118.7, 114.1, 112.4, 55.3, 33.7, 29.2, 28.9, 28.8, 25.9, 25.0; IR $\left(\mathrm{CHCl}_{3} v_{\text {max }} \mathrm{cm}^{-1}\right): 3077,2927,2854,1619,1577,1480$, 1456, 1428, 1272, 1071, 1003, 931, 788, 750; HR-MS (ESI) $m / z\left[\mathrm{M}+\mathrm{H}^{+}\right]$: calc for $\mathrm{C}_{20} \mathrm{H}_{29} \mathrm{ON}_{4} \mathrm{~S}$ is 373.20566 found $373.20460\left(\mathrm{C}_{20} \mathrm{H}_{29} \mathrm{ON}_{4} \mathrm{~S}\right)$.

\section{MTT assay:}

Cell viability of the synthesized compounds was determined using MTT assay, a colorimetric method ${ }^{[49]}$, 
in which the yellow colored 3-(4,5-di-methylthiazol2-yl)-2,5-diphenyltetrazolium bromide dye is reduced to purple colored formazan crystals by mitochondrial dehydrogenase enzymes. The measure of reduction of MTT to formazan crystals directly correlates with the cell viability. This assay is well-established to determine the cytotoxic nature of drugs. Briefly, the cells were cultured in Dulbecco's modified Eagle's medium in a humidified incubator maintained at $37^{\circ}$. Further, the cells were seeded at a density of $10 \times 10^{3}$ cells per well in 96-well plates and grown for $24 \mathrm{~h}$. The cells were then incubated with the series of compounds for $48 \mathrm{~h}$. After incubation period, MTT $(0.5 \mathrm{mg} / \mathrm{ml})$ was added to each well of the plate by removing the old media and incubated in dark for $4 \mathrm{~h}$. The in situ formed formazan crystals were solubilized to a purple color dye by adding dimethyl sulfoxide (DMSO):methanol $(1: 1 ; \mathrm{v} / \mathrm{v})$ solvent mixture to the wells and kept on the shaker for homogeneous mixing for a few minutes. The absorbance of the samples was measured at $570 \mathrm{~nm}$ using a Synergy H1 multimode plate reader. All the experiments were carried out in triplicate and the results were expressed as normalized viability.

\section{RESULTS AND DISCUSSION}

Twenty target compounds were synthesized as outlined in fig. 1. The starting material undec-10-enoic acid was converted to the methyl ester (2) by reacting with few drops of concentrated sulphuric acid in methanol. This ester was treated with hydrazine hydrate to yield undec10-enehydrazide (3). Undec-10-enehydrazide was reacted with carbon disulfide in presence of potassium

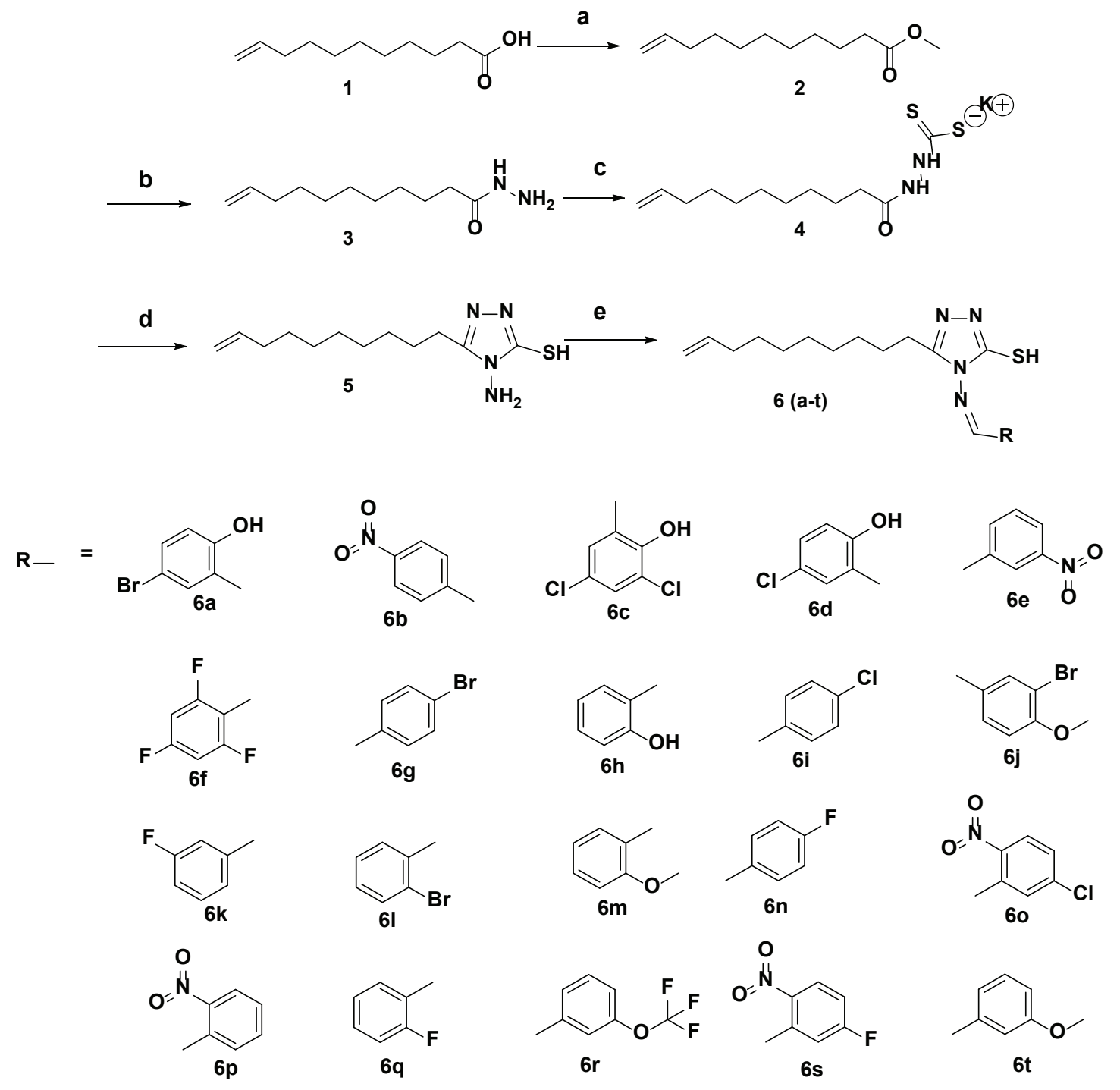

Fig. 1: Reagents and conditions

(a) $\mathrm{MeOH}, \mathrm{H}_{2} \mathrm{SO}_{4}$, reflux, $10 \mathrm{~h}$; (b) hydrazine hydrate, EtOH, reflux, 10h; (c) $\mathrm{CS}_{2}$, KOH, EtOH, RT, 8 h; (d) hydrazine hydrate, reflux, $5 \mathrm{~h}$; (e) aldehyde, $\mathrm{EtOH}, \mathrm{H}_{2} \mathrm{SO}_{4}$, reflux, $6 \mathrm{~h}$ 
hydroxide in ethanol to afford potassium 2-(undec10-enoyl)hydrazine-1-carbodithioate (4). The triazole (5) was obtained by refluxing the potassium 2-(undec10-enoyl)hydrazine-1-carbodithioate in presence of hydrazine hydrate. Further, a new series of Schiff's base derivatives (6a-t) were prepared by treating triazole with equimolar amounts of the selected benzaldehydes in presence of catalytic quantity of sulphuric acid and ethanol under reflux conditions. The synthesized compounds were characterized by ${ }^{1} \mathrm{H},{ }^{13} \mathrm{C}$ NMR, ESIMS, HRMS and IR spectral analysis.

MTT assay was performed in order to determine the cytotoxic effect of synthesized compounds on cancerous and normal cells. The cytotoxic effect of the synthesized compounds (6a-t) $(1$ and $10 \mu \mathrm{M})$ was determined against different cancer cell lines, B16 F10 (mouse melanoma cell line), HCT-15 (human colon cancer cells), SKOV3 (human ovarian cancer cell line) and a normal cell line NIH-3T3 (mouse embryonic fibroblasts) using MTT assay. The results of the MTT assay on various cell lines are shown in fig. 2. The effect of the synthesized compounds on colon cancer cells (HCT-15) is shown in fig. 2A. Among all the tested samples, compounds $6 \mathrm{i}, 6 \mathrm{n}, 6 \mathrm{o}, 6 \mathrm{p}$ and $6 \mathrm{q}$ were found to be cytotoxic to HCT-15 cells (fig. 2A). DMSO served as the vehicle control and doxorubicin (DOX: $2.5 \mu \mathrm{M}$ ) served as the positive control. In all the experiments untreated control cells were designated as UT. Fig. 2B demonstrated the cytotoxic effect of the compounds on the viability of mouse melanoma cells (B16 F10). Among the tested compounds, 6g and 6n exhibited significant cytotoxicity against B16 F10 cells (fig. 2B) and particularly compound $6 \mathrm{~g}$ exhibited better cytotoxicity against B16 F10, which might be due to enhanced uptake of $6 \mathrm{~g}$ by B16 F10 cancer cells and it is noteworthy that $6 \mathrm{~g}$ has a bromo substitution at $4^{\text {th }}$ position. The cytotoxicity of compounds $6 \mathrm{i}, 6 \mathrm{n}, 6 \mathrm{o}, 6 \mathrm{p}$ and $6 \mathrm{q}$ might be attributed to the presence of 4-chloro, 4-fluoro, 5-chloro-2-nitro, 2-nitro and 2-fluoro substitutions, respectively.

The effect of the synthesized compounds on the viability of SKOV3 ovarian cancer cells is shown in fig. 2C, which surprisingly demonstrated that none of the compounds exhibited cytotoxicity to SKOV3 cancer cells. All the above results support the observation that similar compounds show difference in their cytotoxic potential towards various cancer cell types as reported in the literature ${ }^{[50]}$. In spite of effective cytotoxic nature of commercial anticancer agents towards cancer cells, severe cytotoxicity

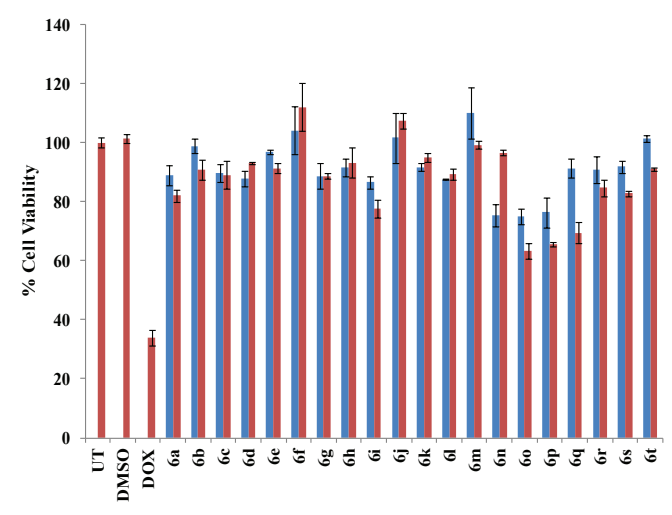

A

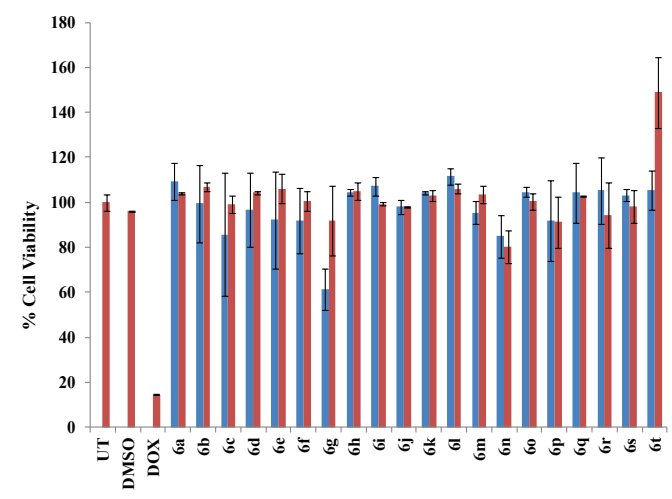

B

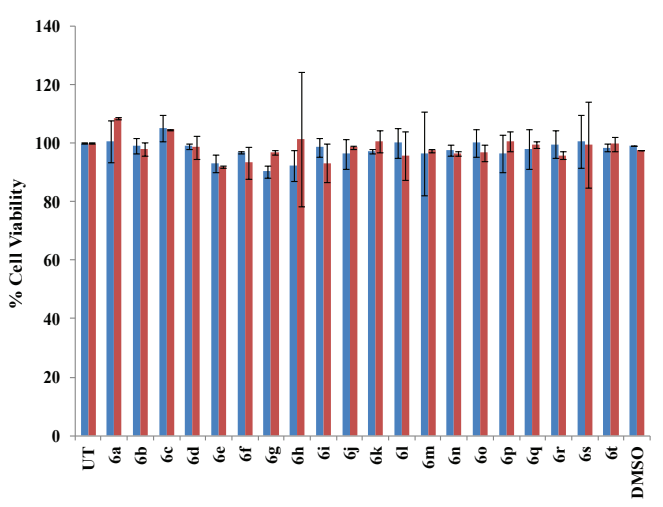

C

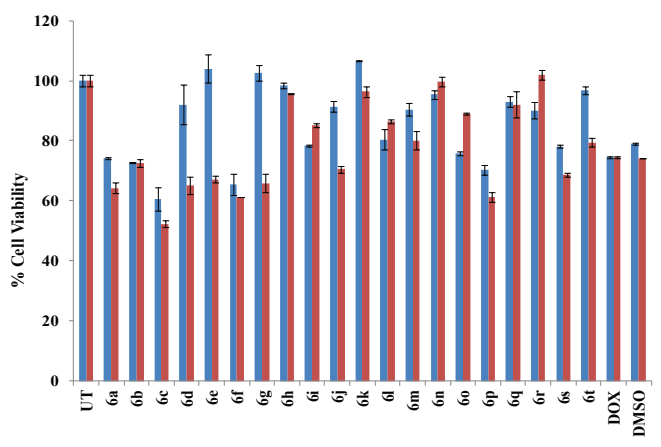

D

Fig. 2: Determination of cytotoxic effect of compounds $6 a-6 t$ using MTT assay

A. HCT-15 cells viability, B. B16 F10 cells viability, C. SKOV3 cells viability, D. NIH 3 T3 cells viability, $\approx 1 \mu \mathrm{M}, \approx 10 \mu \mathrm{M}$

towards normal cells limits their clinical translation. In order to check the effect of the synthesized compounds on normal cells, MTT assay was performed using NIH 3T3 mouse embryonic fibroblasts and the results are 
shown in fig. 2D. According to the assay results, the active compounds, which were cytotoxic to cancer cells $(6 \mathrm{~g}, 6 \mathrm{n}$ and $6 \mathrm{q})$ were found nontoxic to normal cells (NIH 3T3), especially at low concentration (fig. 2D), and this observation makes them ideally suited for further development.

In conclusion, a series of novel 1,2,4-triazolebased Schiff's base heterocycles were synthesized. Cytotoxicity of all the synthesized compounds was tested against three cancer cells and a normal cell line. In this study, 4-bromo, 4-chloro, 4-fluoro, 5-chloro-2nitro, 2-nitro and 2-fluoro substitution-based Schiff's base derivatives exhibited significant cytotoxicity; however, 4-bromo derivative exhibited more selective cytotoxicity to cancer cells. Majority of these active compounds were non-toxic to the normal cells, which makes them suitable for further development. Taken together, the observations of cytotoxic nature of these compounds against cancer cells, indicate preliminary anticancer properties.

\section{Acknowledgments:}

Venepally Vijayendar acknowledges the University Grants Commission (UGC), New Delhi, India, for the financial support extended in the form of Senior Research Fellowship (SRF). The CSIRIICT Manuscript Communication Number: IICT/ Pubs./2018/063.

\section{Conflict of interest:}

There are no conflicts of interest.

\section{Financial support and sponsorship:}

Nil.

\section{REFERENCES}

1. Turan-Zitoun G, Kaplancikl ZA, Yildiz MT, Chevallet P, Kaya D. Synthesis and antimicrobial activity of 4-phenyl/ cyclohexyl-5-(1-phenoxyethyl)-3-[N-(2-thiazolyl)acetamido] thio-4H-1,2,4-triazole derivatives. Eur J Med Chem 2005;40:607.

2. Walczak K, Gondela A, Suwinsk J. Synthesis and antituberculosis activity of N-aryl-C-nitroazoles. Eur J Med Chem 2004;39:849.

3. Holla SB, Veerendra B, Shivananda MK, Poojary B. Synthesis characterization and anticancer activity studies on some Mannich bases derived from 124-triazoles. Eur J Med Chem 2003;38:759-67.

4. Amir M, Shikha K. Synthesis and anti-inflammatory analgesic ulcerogenic and lipid peroxidation activities of some new 2-[(26-dichloroanilino) phenyl]acetic acid derivatives. Eur J Med Chem 2004;39:535-45.
5. Almasirad A, Tabatabai SA, Faizi M, Kebriaeezadeh A, Mehrabi N, Dalvandi A, et al. Synthesis and anticonvulsant activity of new 2-substituted-5- [2-(2-fluorophenoxy)phenyl]134-oxadiazoles and 124-triazoles. Bioorg Med Chem 2004;14(24):6057.

6. George T, Mehta DV, Tahilramani R, David J, Talwalker PK. Synthesis of some s-triazoles with potential analgetic and antiinflammatory activities. J Med Chem 1971;14:335-8.

7. Nawwar GA, Haggag BM, Swellem RH. Synthesis and molluscicidal activity of new derivatives of 1-(hydroxy/ substituted phenyl)-3-arylpropenones. Arch Pharm 1993;326:831-6.

8. Grant N, Mishriky N, Asaad FM, Fawzy NG. Pyridines and pyrazolines from salicylic acid derivatives with propenone residue and their antimicrobial properties. Pharmazie 1998;53:543-7.

9. Shafik NA, Chabaka LM, Nawwar GAM. Salicylanilides and their heterocyclic analogues with molluscicidal activity. Afinidad 2006;63:523.

10. Nawwar GAM, Chabaka LM, Shafik NA, Hany MS. Oximinosalicylanilide like analogues as molluscicidal agents. Afinidad 2006;63:153.

11. Duran A, Dogan HN, Rollas S. Synthesis and preliminary anticancer activity of new 14-dihydro-3-(3-hydroxy-2naphthyl)-4-substituted-5H-124-triazoline-5-thiones. Farmaco 2002;57:559-64.

12. Aytac SP, Tozkoparan B, Kaynak FB, Aktay G, Goktas O, Unuvar S. Synthesis of 3, 6-disubstituted 7H-124-triazolo[34b]-134-thiadiazines as novel analgesic/anti-inflammatory compounds. Eur J Med Chem 2009;44:4528.

13. Prakash O, Aneja DK, Hussain K. Synthesis and biological evaluation of dihydroindeno and indeno [12-e] [124]triazolo [34-b] [134]thiadiazines as antimicrobial agents. Eur J Med Chem 2011;46:5065.

14. Altıntop MD, Kaplancıklı ZA, Turan-Zitouni G, Özdemir A, İscan $\mathrm{G}$, Akalın $\mathrm{G}$, et al. Synthesis and anticandidal activity of new triazolothiadiazine derivatives. Eur J Med Chem 2011;46:5562-6.

15. Mohammad R, Ali S, Mahsa R, Mehdi B. Synthesis and antibacterial evaluation of new heterocyclic system: [124] triazolo-[3' 4':6 1] pyridazino-[4 3-e] [134] thiadiazine. Heterocycl Commun 2012;18:39.

16. Badr SMI, Barwa RM. Synthesis of some new [124] triazolo[34-b][134]thiadiazines and [124]triazolo[34-b] [134] thiadiazoles starting from 5-nitro-2-furoic acid and evaluation of their antimicrobial activity. Bioorg Med Chem 2011;19:4506.

17. Suresh Kumar GV, Rajendra Prasad Y, Mallikarjuna BP, Chandrashekar SM. Synthesis and pharmacological evaluation of clubbed isopropylthiazole derived triazolothiadiazoles triazolothiadiazines and mannich bases as potential antimicrobial and antitubercular agents. Eur J Med Chem 2010;45:5120-9.

18. El Shehry MF, Abu-Hashem AA, El-Telbani EM. Synthesis of 3-((24-dichlorophenoxy)methyl)-124-triazolo(thiadiazoles and thiadiazines) as anti-inflammatory and molluscicidal agents. Eur J Med Chem 2010;45:1906-11.

19. Holla BS, Akberali PM, Shivananda MK. Studies on nitrophenylfuran derivatives part Xii. synthesis characterization antibacterial and antiviral activities of some nitrophenylfurfurylidene-124-triazolo[34-b]-134thiadiazines. Farmaco 2001;56:919-27. 
20. Al-Masoudi NA, Al-Soud YA. New sulfonamide and carboxamide derivatives of acyclic C-nucleosides of triazolothiadiazole backbones and the thiadiazine analogues. Synthesis and anti-HIV activity. Nucleosides Nucleotides Nucleic Acids 2008;27:1034-44.

21. Dutta K, Rangarajan PN, Vrati S, Basu A. Japanese encephalitis: pathogenesis prophylactics and therapeutics. Curr Sci 2010;98:326.

22. Khan I, Ali S, Hameed S, Rama NH, Hussain MT, Wadood A. Synthesis antioxidant activities and urease inhibition of some new 124-triazole and 134-thiadiazole derivatives. Eur J Med Chem 2010;45:5200-7.

23. Barbuceanu SF, Saramet G, Almajan GL, Draghici C, Barbuceanu F, Bancescu G. New heterocyclic compounds from 124-triazole and 134-thiadiazole class bearing diphenylsulfone moieties. Synthesis characterization and antimicrobial activity evaluation. Eur J Med Chem 2012;49:417.

24. El-Ebiary Nora MA, El-Telbani EM, Nawwar GAM. Design Synthesis Crystal Structure and Antimicrobial Evaluation of Novel Pyrazolyl-135-oxadiazoles Pyrazolyl-124-triazoles and their Related Thioglycosides. Lett Drug Des Discov 2013;10:444.

25. Sathe BS, Jaychandran E, Jagtap VA, Sreenivasa GM. Synthesis characterization and anti-inflammatory evaluation of new fluorobenzothiazole schiff's bases. Int J Pharm Res Devel 2011;3:164.

26. Sondhi SM, Singh N, Kumar A, Lozach O, Meijer L. Synthesis anti-inflammatory analgesic and kinase (CDK-1 CDK-5 and GSK-3) inhibition activity evaluation of benzimidazole/ benzoxazole derivatives and some Schiff's bases. Bioorg Med Chem 2006;14:3758-65.

27. Pandey A, Dewangan D, Verma S, Mishra A, Dubey RD. Synthesis of Schiff bases of 2-amino-5-aryl-134-thiadiazole And its Analgesic Anti-Inflammatory Anti-Bacterial and AntiTubercular Activity. Int J ChemTech Res 2011;3:178.

28. Chandramouli C, Shivanand MR, Nayanbhai TB, Bheemachari B, Udupi RH. Synthesis and biological screening of certain new triazole schiff bases and their derivatives bearing substituted benzothiazole moiety. J Chem Pharm Res 2012;4:1151.

29. Chinnasamy RP, Sundararajan R, Govindaraj S. Synthesis characterization and analgesic activity of novel schiff base of isatin derivatives. J Adv Pharm Technol Res 2010;1:342-7.

30. Mounika K, Anupama B, Pragathi J, Gyanakumari C. Synthesis characterization and biological activity of a Schiff base derived from 3-ethoxy salicylaldehyde and 2-amino benzoic acid and its transition metal complexes. J Sci Res 2010;2:513.

31. Venkatesh P. Synthesis characterization and antimicrobial activity of various schiff bases complexes of $\mathrm{Zn}$ (II) and $\mathrm{Cu}$ (II) ions. Asian J Pharm Health Sci 2011;1:8.

32. Chaubey AK, Pandeya SN. Synthesis \& anticonvulsant activity (Chemo Shock) of Schiff and Mannich bases of Isatin derivatives with 2-Amino pyridine (mechanism of action). Int J PharmTech Res 2012;4:590.

33. Aboul-Fadl T, Mohammed FA, Hassan EA. Synthesis antitubercular activity and pharmacokinetic studies of some Schiff bases derived from 1- alkylisatin and isonicotinic acid hydrazide (INH). Arch Pharm Res 2003;26:778-84.

34. Miri R, Razzaghi-asl N, Mohammadi MK. QM study and conformational analysis of an isatin Schiff base as a potential cytotoxic agent. J Mol Model 2013;19:727-35.

35. Ali SM, Azad MA, Jesmin M, Ahsan S, Rahman MM, Khanam $\mathrm{JA}$, et al. In vivo anticancer activity of Vanillin semicarbazone. Asian Pac J Trop Biomed 2012;2:438-42.

36. Wei D, Li N, Lu G, Yao K. Synthesis catalytic and biological activity of novel dinuclear copper complex with Schiff base. Sci China B 2006;49:225-9.

37. Avaji PG, Vinod Kumar CH, Patil SA, Shivananda KN, Nagaraju C. Synthesis spectral characterization in-vitro microbiological evaluation and cytotoxic activities of novel macrocyclic bis hydrazine. Eur J Med Chem 2009;44:3552-9.

38. Li S, Chen S, Lei S, Ma H, Yu R, Liu D. Investigation on some Schiff bases as $\mathrm{HCl}$ corrosion inhibitors for copper. Corrosion Sci J 1999;41:1273.

39. Chohan Z H, Praveen M, Ghaffar A. Structural and biological behaviour of $\mathrm{Co}$ (II) $\mathrm{Cu}$ (II) and $\mathrm{Ni}(\mathrm{II})$ metal complexes of some amino acid derived Schiff-bases. Met Based Drugs 1997;4:267-72.

40. Rauf A, Parveen H. Preparation, characterization and antimicrobial activity of fatty alkenoates. Indian $\mathrm{J}$ Chem 2005;44B:1273.

41. Sharma S, Gangal S, Rauf A. Microwave assisted efficient one-pot synthesis of 3,5,6-trisubstituted-1,2,4-triazines from fatty acid hydrazides under solvent-free conditions and their antimicrobial activity. Arch Org Chem 2007;16:137.

42. Ahmed SM, Ahmad F, Osman SM. Preparation and characterization of derivatives of isoricinoleic acid and their antimicrobial activity. J Am Oil Chem Soc 1985;62:1578.

43. Khan MYW, Ahmad F, Ahmad I, Osman SM. Nonedible seed oils as insect repellent. J Am Oil Chem Soc 1983;60:949.

44. Rahman VPM, Mukhtar S, Ansari WH, Lemiere G. Synthesis, stereochemistry and biological activity of some novel long alkyl chain substituted thiazolidin-4-ones and thiazan-4one from 10-undecenoic acid hydrazide. Eur J Med Chem 2005;40:173-84.

45. Dolezalova M, Janis R, Svobodova H, Kasparkova V, Humpolicek P, Krejci J. You have full text access to this content Antimicrobial properties of 1-monoacylglycerols prepared from undecanoic (C11:0) and undecenoic (C11:1) acid Eur J Lipid Sci Technol 2010;112:1106.

46. Tokiwa Y, Kitagawa Y, Raku M, Yanagitani TS, Yoshino K. Enzymatic synthesis of arbutin undecylenic acid ester and its inhibitory effect on melanin synthesis. Bioorg Med Chem Lett 2007; 17:3105.

47. Nagao Y, Mustafa J, Sano S, Ochiai M, Tazuko T, Shigeru T. Different Mechanism of Action of Long Chain Fatty Acid Esters of Podophyllotoxin and Esters of Epipodophyllotoxin Against P388 Lymphocytic Leukemia in Mice. Med Chem Res 1991;1:295-9.

48. Lie Ken Jie MSF, Mustafa J, Pasha MK. Synthesis and Spectral Characteristics of Some Unusual Fatty Esters of Podophyllotoxin. Chem Phys Lipids 1999;100:165.

49. Nethi SK, Rico-Oller B, Rodríguez-Diéguez A, GómezRuiz S, Patra CR. Design, synthesis and characterization of doped-titanium oxide nanomaterials with environmental and angiogenic applications. Sci Total Environ 2017:599:1263.

50. Sak K. Cytotoxicity of dietary flavonoids on different human cancer types. Pharmacogn Rev 2014;8:122. 